\title{
魚類の簡易衛生學的細菌檢查法に就いて
}

\author{
䦭根隆 -中篗男 \\ (東京水应大学)
}

\author{
On Simple Hygienic Examination \\ Method of Bacteria for Fish \\ Yutaka SEKINE and Toshio Nakakupo
}

In order to examire frech fish and oiter marine products, scratch method is adopted at present. But this method proved not too gcod, because it takes 4 or 5 days to gone through while fresh fish should be examined in a very short time.

According to this idea we devised the paper-pasting method to shorten the time required. First, parchment paper of 2.0 by $2.5 \mathrm{~cm}$. in size should be sterilized.

If $\mathrm{fish}$ is small, medium, or large, 1, 2 or 4 pieces of paper respectively should be pasted on each side of fish, and ransplated on Endo or E.M.B. agat plate, then following is same manner to scratch method. Our method is simple in operation and does not need B. G. L.B. fermentation tube, then also talkes less time it better than the old.

As a result of a comparison made between the two method, there was found little difference as to the efficiency for detecting colon group.

\section{I. 緒豆}

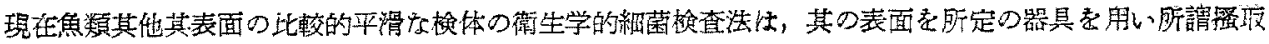

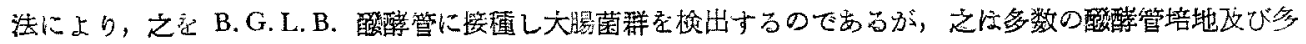

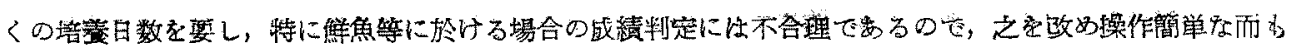

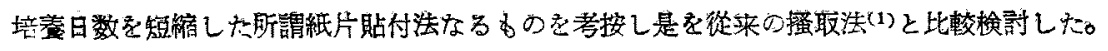

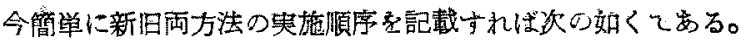

Table 1. (Scratth method)

Surface of fish $\left(120 \mathrm{~cm}^{2}\right)-\mathrm{NaCl}(100 \mathrm{cc})-$ B. G. L. B. -
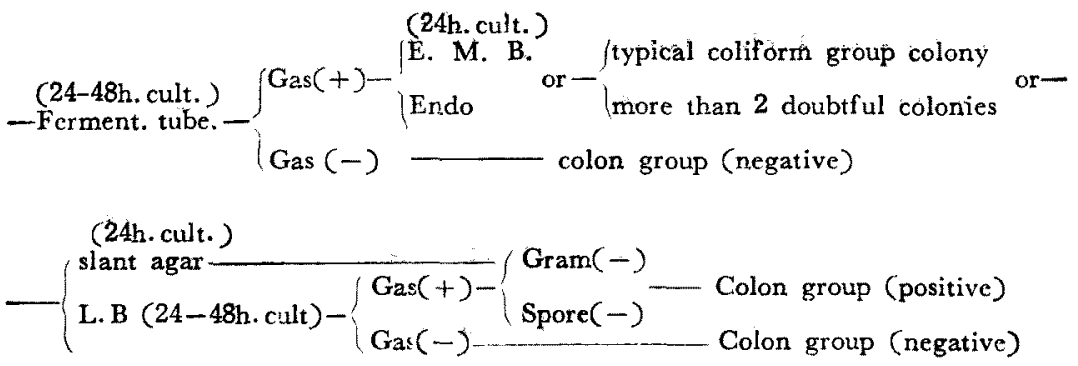

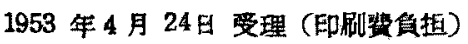




\section{(Paper-pasting method)}
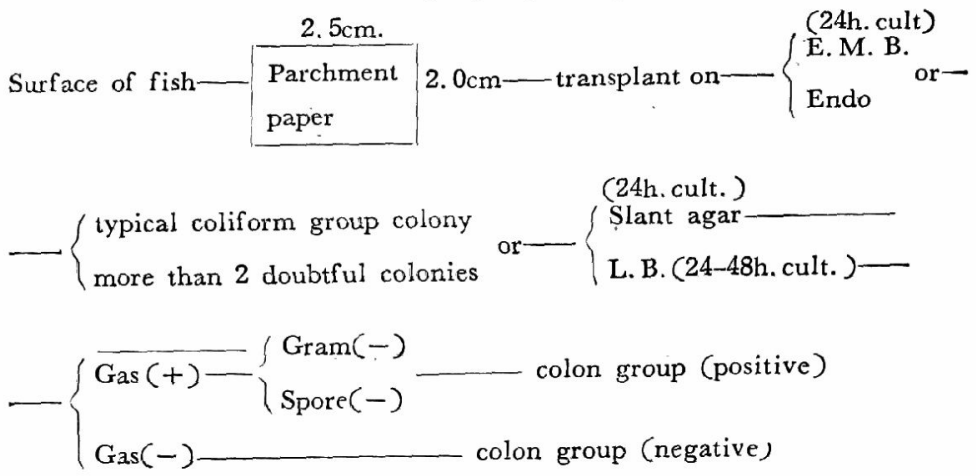

\section{II. 新旧兩方法の菌检出比較}

\section{（1）兴験方法}

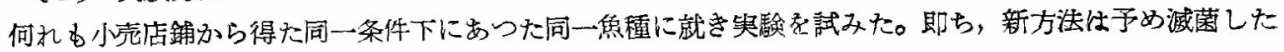
$2.0 \times 2.5 \mathrm{~cm}$ 大の硫酸紙（シャーレ1枚に 4 枚貼付し得る）文

小形魚に注片側に1枚両側で 2 枚

中形魯 " 2 枚" 4 枚
大形魚 " 4 枚" 8 枚貼付 L,

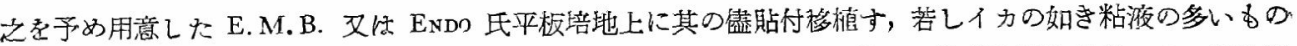

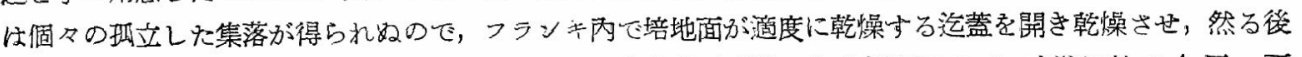

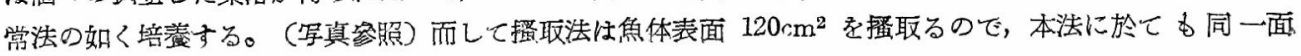
積で比較した。

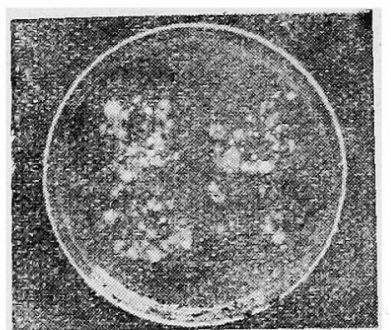

Mackerel

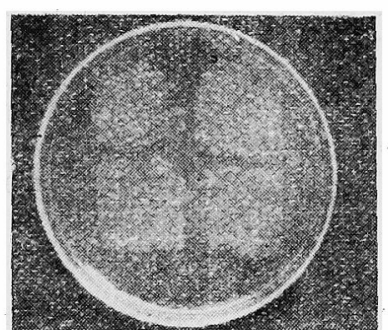

Cuttle fish

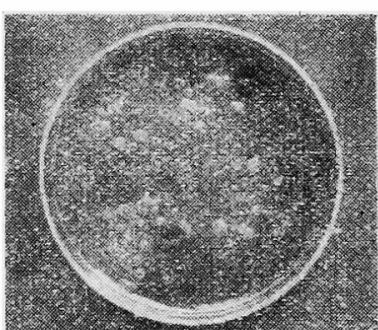

Sardine

\section{（2）実験成績}

両法据比較した個々の魚体に就いてほ前記の如く全く同一材料ではないが，第2 表の如く其の成績は両者 間に大差なく，又検出した菌種に於ても㠰ど差暴以認められなかつた。

\section{III. 兩檢楂法による採菌能渠}

（1）些臨方法

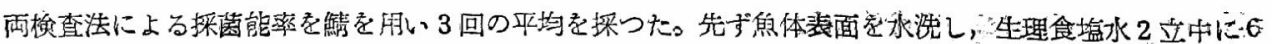




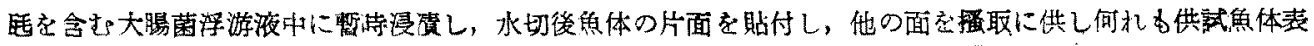

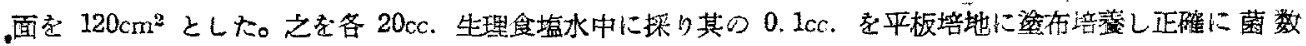

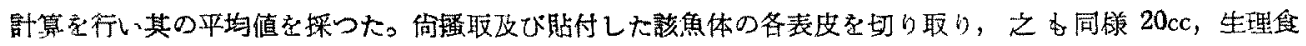

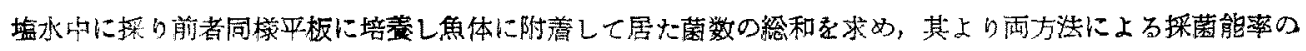
割合を出した。

Table 2. Record of Old and New Methods (by Imvic system).

\begin{tabular}{|c|c|c|}
\hline Kind of fish & Paper-pasting method & Scratch method \\
\hline Mackerel & Intermediate II type & Intermediate II lype \\
\hline "l & $" 1$ & E. coli I type \\
\hline$" \prime$ & A. aerog. II type & A. aerog. I type \\
\hline$"$ & Intermediate II type & $\cdots "$ \\
\hline$" \prime$ & " & II type \\
\hline " & I type & Intermediate I type \\
\hline$" l$ & "II type & $\prime \prime$ \\
\hline Cuttle fish & B. coli I type & II type \\
\hline$" r$ & $\prime \prime$ & E. coli I type \\
\hline$" \prime$ & Intermediate I type & Intermediate I type \\
\hline " & A. acrog. I ype & II type \\
\hline$" 1$ & B. coli I type & I type \\
\hline$"$ & A. aerog. I type & E. coli I type \\
\hline "1 & $\prime \prime$ & Intermediate I type \\
\hline Sardine & Intermediate I type & II type \\
\hline ' & A. aerog. I type & A. aerog. I type \\
\hline $\begin{array}{l}\text { Fish minced and } \\
\text { steamed }\end{array}$ & E. coli Il type & Intermediate II type \\
\hline Fish pudding & None & None \\
\hline
\end{tabular}

(2) 突駼成得 右落の如く旧法性新法上

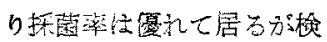

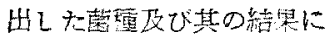

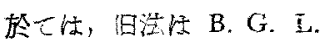
B. の橧菌用培地定用いる

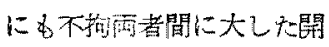
Table 3. Efficiency of Old and New Methods (average of 3 tests). き纹譛女られなかつた。

\begin{tabular}{l|c|c|c}
\hline Mackerel & Paper-pasting & Remainding bacteria & Efriciency \\
& 18 & 114 & $14 \%$ \\
& Scratching & Remainding bacteria & Efficiency \\
& 27 & 117 & $20 \%$ \\
\hline
\end{tabular}

\section{IV. 稜 括}

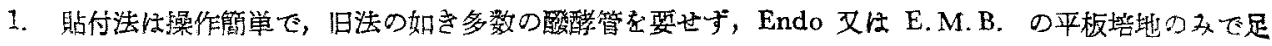
b。

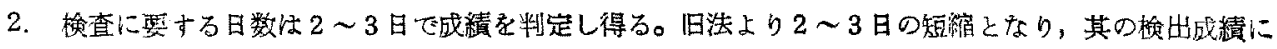

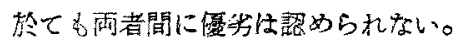

3. 本法に上万魚体検目全表面積忙 $200 \mathrm{~cm}^{2}$ 索可とする。即ち 


$$
\begin{aligned}
& \text { 小形魯 } 20 \text { 尾 } \times 2 \text { 枚 } \times 5 \mathrm{~cm}^{2}=200 \mathrm{~cm}^{2} \\
& \text { 中" } 10 \times 4 \text { 枚 } \times 5 \mathrm{~cm}^{2}=200 \mathrm{~cm}^{2} \\
& \text { 大" } 5 \text { 尾 } \times 8 \text { 故 } \times 5 \mathrm{~cm}^{2}=200 \mathrm{~cm}^{2}
\end{aligned}
$$

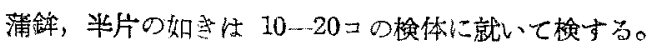

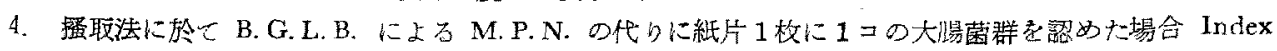

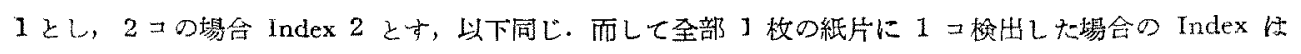

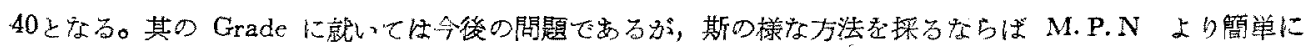
其のIndex 算出し得る。

$$
\text { 妾献 }
$$

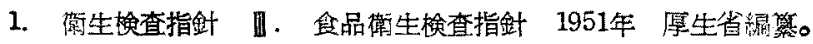

